\title{
Music Genre as Method
}

\section{TIMOTHY LAURIE}

UNIVERSITY OF MELBOURNE

Jennifer C. Lena

Banding Together: How Communities Create Genres in Popular Music

Princeton University Press, New Haven, 2012

ISBN 9780691150765

RRP US $\$ 37.50$

Michelle Phillipov

Death Metal and Music Criticism: Analysis at the Limits

Lexington Books, UK, 2012

ISBN 9780739197608

RRP US $\$ 39.99$

Graham St John

Global Tribe: Technology, Spirituality and Psytrance

Equinox Publishing, UK, 2012

ISBN 9781845539566

RRP US $\$ 29.95$

ISSN 1837-8692

Cultural Studies Review 2014. @ 2014 Timothy Laurie. This is an Open Access article distributed under the terms of the Creative Commons Attribution 4.0 Unported (CC BY 4.0) License

(https://creativecommons.org/licenses/by/4.0/), allowing third parties to copy and redistribute the material in any medium or format and to remix, transform, and build upon the material for any purpose, even commercially, provided the original work is properly cited and states its license.

Citation: Cultural Studies Review (CSR) 2014, 20, 4149, http://dx.doi.org/10.5130/csr.v20i2.4149 
Writing about popular culture always involves inclusions and exclusions. In popular music studies, these inclusions and exclusions are often made tacitly through the use of genre taxonomies, ranging from the broad (pop, rock, jazz) to the highly specific (the Gothenburg sound, Hi-NRG, Krautrock). Since the early 1980s, genre has graduated from being a subset of popular music studies to being an almost ubiquitous framework for constituting and evaluating musical research objects. One rarely has to make a general case for genre, so long as one can tell persuasive stories about what genres mean in cultural context: metal as transgressive, hip hop as community building, punk as counter-hegemonic, and so on. Jennifer Lena's Banding Together, Graham St John's Global Tribe and Michelle Phillipov's Death Metal and Music Criticism each employ genre as a principle of selection and hence raise questions about the strengths and limitations of genre criticism as a heuristic method in popular music studies.

Jennifer Lena's Banding Together analyses 'how music communities in general operate: what shared obstacles and opportunities creative people face, what debates tend to characterise different states of the field, and so forth'. (3) According to Lena, musical communities are predisposed to genre formation, since they exist 'when there is some consensus that a distinctive style of music is being performed'. (6) These genre-based communities are in turn classified by Lena as avant-garde (loosely experimental or innovation-centred), scene-based (locally networked music practices), industry-based (explicitly commercial), or traditionalist (historically preservationist or conservative). Each community generates distinct criteria for classifying musical objects: fro example, avant-gardists focus on originality, while industry-based music communities focus on commercial viability. Having outlined this schema in the introduction, Banding Together then elaborates on numerous genre communities with case studies ranging from within the US music industry (P*Funk and Crosby, Stills and Nash) in a chapter on music and the State taking its examples from Chile, China, Nigeria and Serbia.

To explain the social production of genres, Banding Together sustains four normative premises about how musical communities work. First, genres 'emerge out of creative circles where potential innovators interact in face-to-face settings' (161); second, people listen to music based on genre classifications; third, people seek to form collective agreements about music genres; and fourth, commercial life 
intervenes in the 'commodification' of music but not in the identities, aspirations or habits of those who make or consume music. Innate social tendencies towards creativity, classification, consensus and autonomy are thus at the heart of Lena's vision of creative musical communities. Consequently, the themes of social contradiction, antagonism and social (mis)recognition found in the work of sociologists like Dick Hebdige or Sarah Thornton do not figure in Banding Together, and this leaves more space available for Lena to construct elegant typologies and taxonomies of musical practices. Felt throughout the book is the influence of twentieth-century economist Joseph Schumpeter, whose speculative inferences about 'creative destruction' and innate social 'inventiveness' have shaped the works of popular music scholars like Richard A. Peterson and others working under the creativity and innovation umbrella. Like Schumpeter and his successors, Lena is eager to infer the existence of social relationships through normative categories such as 'innovation', 'community' and 'consensus'. Unfortunately, Banding Together is unable to define these terms without redundancy. Genres and innovations within genres are defined as whatever communities or stakeholders consider them to be, and communities are defined loosely as stakeholders or participants in a given musical genre. This circularity would be interesting if interrogated, but it is not. Lena's meditation on the State provides the most promising exit from this analytical loop but, for the most part, it becomes difficult to grasp any of these categories outside this tightly wound circuit of mutually dependent terms.

The schematic ambitions of Banding Together contrast sharply with St John's Global Tribe, which is part music history and part cultural anthropology. Peppered with anecdotes from artist biographies and animated throughout by gonzoesque storytelling, it takes as its genre object psytrance and, in particular, the legacy of 1970s Goatrance in the contemporary festival circuit as it spans Australia, Israel and Portugal. When not narrating genre history, Global Tribe considers a series of oppositions between local and global, self and tribe, spiritual and technological, transgressive and progressive, roots and novelty, commercial and independent. (8) These tensions are invoked by the 'liminal' or 'planetary' cultures of psytrance, which St John explores through close analyses of Goa Gil and his critics and, in one compelling example, through a failed Zionist psytrance festival in Israel. (118) The sections on festivals would make an appropriate entry-point for readers unfamiliar 
with psytrance or for those interested in developing ethnographies of global music events and circuits.

Though St John's account of psytrance events, celebrity artists and local histories is absorbing, Global Tribe is less convincing when drawing wider social implications from this material. According to St John, the Goa-based trance practices of the 1970s and 1980s were formative events for North American and European travellers and facilitated 'freedoms from nuclear family, organized religion, state surveillance and normative modes of subjectivity'. (68) Goatrance is cast as:

music born from a privileged experiment where middle-class youth choosing their exit sought freedoms not only from moral injunctions, state surveillance, wage slavery and patriotism, but liberation from the illusion of their own separation: their minds from their bodies, consciousness from physical matter, a dissonance which was expressed in the joyful contagion of dance. (72)

Later we are advised that the 'temporary dispossession from routine subjectivity, labour practices and legitimate citizenship should not be undervalued' because 'the attendants and occupants of such temporalities find ways to smuggle the "weekend" ethos back across the border'. (217) Global Tribe amplifies optimistic claims about the ethical potential of psytrance participation, suggesting, among other things, that 'liminars are released from the abstractions of the everyday', (302) that 'psytrance makes possible the transcendence of normative embodiment, subjectivity and citizenship', (312) and that 'Visionaries, ideologues and stalwarts of independence are determined to maintain their integrity in response to a variety of threats'including the threats of 'soulless conformity, proprietary sensibilities, interventions of the state, untoward exposure, and predatorial behaviour'. (334)

While providing numerous thick descriptions of the weekend ethos at psytrance festivals, Global Tribe is much less interested in the weekdays. Except for a brief discussion of music in the lives of young Israeli soldiers, St John does not provide any specific social, cultural or historical content to substantiate regular indictments of 'normative subjectivity' and 'everyday abstractions'. The author's dynamic prose slips from documenting and historicising counter-cultural narratives of anti-conformity to accepting, even endorsing, the conspicuously flimsy renditions of the world that psytrance participants are supposed to have left behind. 
Nevertheless, Global Tribe gives many examples of social relationships constituted in and through genre-specific musical practices. If only it paid the same attention to the afterlives of music festivals, we might come closer to understanding whether psytrance actually produced long-lasting commitments to challenging social hierarchies.

The questions around genre and community raised by Lena and St John are given a different inflection in Michelle Phillipov's Death Metal and Music Criticism . Alongside Harris M. Berger's Metal, Rock, and Jazz, Death Metal and Music Criticism is one of the few publications that considers heavy metal music in relation to other more commonly studied genres, such as punk, hip hop and electronic dance music (EDM). ${ }^{1}$ More critically oriented than Banding Together or Global Tribe, Phillipov's book links a diversity of genre-based studies to 'a broader tendency within popular music studies to prioritise political concerns over questions of musical pleasure'. (xii) One example provided of excessive political partisanship is John Charles Goshert's endorsement of the 'essential radicalism' of scene-based punk, which defines what 'counts as punk' as 'simply that which takes place at punk shows', a definition 'determined not by musical genre but by political orientation'. (31) In hip hop studies, too, the much touted political radicalism of Public Enemy has an ambiguous relation to the mostly white, middle-class American youths who have historically been the primary buyers of the group's recordings. At the same time, earlier Frankfurt School approaches to popular music are criticised for their political evaluations of 'working-class youth' and the 'popular culture they enjoyed' which is too quickly characterised by Theodor Adorno and friends as 'indicative of their surrender to social and economic inequality'. (3)

Heavy metal provides the most dramatic case of this politicising tendency. As Phillipov observes, scholars in the field have often tended 'to assume that music should in some way address and resist social inequality' and many commentaries 'often serve less as an explanation for metal than as an evaluation of it'. (xviii) By contrast, Death Metal and Music Criticism examines canonical recordings by Cannibal Corpse and Carcass with a seriousness rarely afforded to death metal artists. Through close readings of lyrical form and musical devices, Phillipov generates a relatively autonomous schema of aesthetic appreciation for a genre outside the dominant field of cultural production and beyond the familiar coordinates of 
political signification. Phillipov's argument, that death metal genres produce original parameters for musical appreciation and pleasure, provides an important corrective to readings of metal that overstate its transgressions of musical norms.

The polemical claims of Death Metal and Music Criticism are novel in the context of popular music studies, although not for its estranged cousin, philosophical aesthetics. The first half of the text lucidly reiterates the Kantian critique of judgement: namely, that neither reasoning nor understanding should be allowed to pre-empt the meanings of a work of art, and that instrumental attitudes to aesthetic experiences preclude the important speculative, imaginative and ethical possibilities that art can make available. Although Phillipov makes frequent reference to the 'pleasures' of death metal, the pleasures on offer are decidedly enlightened ones. In her account, death metal listeners are seemingly preoccupied with the forms and techniques of musical works. These aficionados develop a reliable capacity for 'death metal appreciation', (96) tending 'not to let the sound simply wash over them, but rather listen[ing] actively and attentively'. (104) Specialised musical cultivation allows the ideal metal listener to refuse a stable listening position in favour of genre literacy as 'comprehended by those who have invested time, effort, and commitment' (83) to 'musical complexity' (122) and the 'pleasures of technical appreciation'. (132) Phillipov elsewhere suggests that, in the case of death metal, appreciating 'complexity and precision' is 'less about creating oppressive social hierarchy than alternative forms of listening experience' that may 'enable participants to escape from any kind of straightforward political positioning'. (64-5)

The sceptical reader might wonder what distinguishes the technical 'appreciation' of death metallers from that famously criticised by Theodor Adorno, who noted the coincidence between alienation in capitalism and the embrace of technical criteria for musical and cinematic achievement. One could also ask whether the Kantian death metaller escapes the numerous criticisms of aestheticism found in Pierre Bourdieu's readings of taste-based social hierarchies. The important difference, it seems, is that death metal is relatively autonomous from the 'popular music' considered by Adorno and from the vertical cultural hierarchies mapped by Bourdieu. 
For all its theoretical potential, however, the singularity and autonomy of death metal listening is taken as a premise in Death Metal and Music Criticism, rather than as an empirical question to be investigated. This sometimes leads to egregious contrasts between death metal and a broad-based account of popular music more generally. It is suggested, for example, that in 'most popular music of the past five decades ... the voice is typically the aural and emotional centre'. (76) In comparison, 'the voice in death metal is used not to lend weight to political messages, offer a vehicle for emotional connection and identification, or provide clearly recognisable words or analysable meanings'. (74) In addition to describing vast amounts of jazz, dub and EDM, this latter statement could just as well apply to chunks of recent albums by Beyoncé, Justin Timberlake and Kanye West. Conversely, the comparison also sidelines many vocal-centric, thematically dense recordings by top-selling death metal artists such as Death (The Sound of Perseverance, 1998), Opeth (Blackwater Park, 2001) and even Carcass (Heartwork, 1993), whose CDs are invariably accompanied with printed lyrics. Phillipov's own characterisation of the death metal canon and its ideal listener, and the corresponding restriction of 'popular music' to a 'conventional identificatory logic', is 'determined not by musical genre but by [aesthetic] orientation'. (111) The book provides an argument for how one should listen to death metal, not an assessment of how, in the formation and proliferation of a genre, people actually do listen to death metal.

As both Frankfurt School critics and Birmingham School sociologists have pointed out, partisanship is an unavoidable precondition for making meaningful arguments about popular culture. To accuse punk scholars of defining punk in political terms is, as it turns out, a restatement of the situation that also animates Phillipov's volume: decisions about what counts as 'in' and 'out' of a genre, or who the proper listening subject for a genre should be, always require judgments of some kind. Likewise, 'death metal listening' in the sense Phillipov gives it is less an observable practice than a normative hypothesis. In the spirit of a counterhypothesis, we might leave aside the ideal Carcass fan and speculate that the valuation of instrumental 'complexity' and 'technicality' is but one tendency within a broader practice of technical connoisseurship promoted through a vast array of music magazines and websites, not least the extreme metal monthly, Terrorizer. Both hypotheses are plausible. More importantly, neither overcomes the problem of 
partisanship that Phillipov attributes to-and uses to discredit—punk, hip hop and EDM scholarship.

As disparate as they seem, the three genre studies considered here share certain characteristics. Banding Together defines musical communities normatively, not empirically; Global Tribe endorses the virtues of its musical communities against a backdrop of 'everyday abstractions' that remain elusive; and Death Metal infers its ideal listener from the formal features of art works, themselves carefully selected to support an autonomous vision of the genre in question. In each case, the concept of genre is made to do a lot of work-maybe too much. Studies of music genre have tended to proceed according to three stages. First, the popular music spectrum is divided into genres according to tacit formal criteria. At some point, that is, St John must assert his capacity to recognise psytrance, as must Phillipov with death metal and Lena with funk and jazz. These divisions are then associated with real-world social categories so that musical groupings and social groupings can function interchangeably. St John's psytrance becomes a tribe, Phillipov's death metal a scene, Lena's funk a community. In the third phase, specific signs, events or statements are deemed unique to the music genre and then attributed to the collective unconscious of the associated social group. The unconscious of psytrance resists everyday abstractions, while the unconscious of death metal seeks complexity and aesthetic perfection. Even in the case of Lena's book, references to 'creativity', 'classification' and 'consensus' also describe a collective unconscious of sorts.

Within this tripartite schema, the collective unconscious must remain at least partly unknown to listeners in order for genre criticism to acquire its explanatory power. For example, if the avant-gardists identified by Lena were conscious of their avant-gardism, or traditionalists of their traditionalism, then this consciousness would become a further object of study. Why do some people seek to produce, or to be identified with, the avant-garde while others seek traditional affiliations? Similarly, St John's argument for the utopian features of psytrance requires that participants do not consciously recognise themselves as escapees from normativity. St John's speculations about participants' unconscious motivations ('liberation from the illusion') are made possible precisely by overlooking the conscious interactions psytrance participants have with the institutions that frame Global Tribe's counter- 
cultural narrative: family, religion, the State. Finally, the death metal listener's drive toward the acquisition of technical knowledge, if framed as conscious effort, would need to be connected to the wider cultures that produce death metal as an attractive object in the first place. Theories framed entirely in terms of appreciation, contemplation or reflection risk idealising an implausibly unmotivated listener defined solely through musical objects rather than seeing them as a person for whom complex intentions and motivations produce variable attractions to cultural objects and practices.

Popular music genres do not belong to isolated, self-sufficient communities. People constantly move between environments where diverse forms of music are heard, advertised and accessorised with distinctive iconographies, narratives and celebrity identities that also touch on non-musical worlds. For this reason individual responses to music rarely conform to behavioural dispositions, whether it be consensus-making (Lena), escapism (St John) or cultivated listening (Phillipov). The studies considered here tend to exclude in advance listeners who do not belong to a fixed musical community, just as they overlook people who participate in a musicoriented community without having any ontological commitment to their peers' musical tastes. Only through such exclusions can texts in popular music studies justify their sharp departure from the themes of difference, antagonism and contradiction that have been important to the development of the field overall.

Of course, books on popular music tend to come out badly when judged by what they forget to talk about. Every book leaves out something at some point. To their credit, Banding Together, Global Tribe and Death Metal and Music Criticism provide exciting speculative narratives about how extant genres might function: St John thinks that Goa could provide an originary homeland for psytrance's communitarian ethics; Lena thinks that popular music genres should be organised around innovation and consensus; Phillipov thinks that musical appreciation might still be pursuable outside social hierarchies based on taste, judgment and habitus. In mythologising various genre classifications, these commentaries register a current of optimism in what popular music could be or could become, even if, as I have suggested, the evidence leads to some knots in argumentation. After all, what would genre criticism be without its rhetorical adventures, its imagined communities and idealised listeners, its kernels of folk optimism? The appeal of genre criticism is that 
it makes narratives out of musical worlds that often seem to lack them. My only complaint is that it becomes too easy to guess what these narratives will be, especially when the actors, settings and endings are preselected by the methodologies employed by genre theorists themselves.

Timothy Laurie is a lecturer in Cultural Studies at the University of Melbourne. His research on popular culture has been published in journals including Feminist Media Studies, Social Identities and Cultural Studies Review. He is currently researching interdisciplinary approaches to popular music, with a focus on gender and sexuality in sound and performance.

\section{一NOTES}

${ }^{1}$ Harris M Berger, Metal, Rock, and Jazz: Perception and the Phenomenology of Musical Experience, Wesleyan University Press, New Hampshire, 1999.

\section{-BIBLIOGRAPHY}

Berger, H. M., Metal, Rock, and Jazz: Perception and the Phenomenology of Musical Experience, Wesleyan University Press, New Hampshire, 1999. 